\title{
Research on Examination of Construction Drawings of University Construction Projects
}

\author{
Wenqiang Dang \\ Infrastructure Department, Northwestern Polytechnical University, Xi'an 710072, Shaanxi, China \\ Email: dangwenqiang@nwpu.edu.cn
}

\begin{abstract}
After completing the construction project approval, the universities will entrust a qualified design institute to carry out plan design, preliminary design and construction drawing design. Among them, the construction drawings are used to show the external shape, internal layout, detailed structure, and fixed facilities of the building, and its design depth meets the requirements for guiding construction. Construction drawings are an important basis for universities to compile bills of quantities, launch bidding, and organize construction. They are also a key factor for universities construction projects to achieve quality, investment, and schedule control goals. Therefore, the establishment of a complete construction drawing review mechanism to improve the quality of construction drawings is of great significance to the later project management.
\end{abstract}

Keywords: university construction project, construction drawing review, design quality

\section{Introduction}

In order to ensure the quality and safety of the project,universities will entrust a third-party organization with corresponding qualifications to review construction drawings before construction in accordance with government regulations, so as to correct potential quality and safety hazards and violations of national mandatory standards in construction drawings. It involves the implementation of mandatory specifications in the design of architecture, structures, water supply and drainage, HVAC, electrical, energy saving, civil air defense, and fire protection. If the drawing review is not carried out in accordance with the regulations, it will not be possible to go through the building construction permits. Therefore, this type of review is mandatory, and we call it a mandatory review.

The implementation of mandatory codes in building design is the minimum requirement to ensure the quality and safety of buildings, and is the bottom line of the designer's career. The mandatory inspection cannot find low-level errors such as errors, omissions, and bumps in the drawings, nor can it identify whether the design effect meets the requirements of the user, and cannot meet the control objectives of the universities for the realization of the various projects of the construction project. Therefore, it is not enough to just conduct a strong review of construction drawings.

In the current construction industry market, because supervision and consulting services are often obtained at low prices, the number and quality of engineers assigned to the project are difficult to meet the requirements, and it is actually impossible to provide technical services such as error correction of construction drawings for colleges and universities. Universities need to rely on experienced staff and reliable intelligent tools to complete the error correction of construction drawings.

\section{Advantages of BIM technology in construction drawing review}

According to the projection principle, the construction drawing uses lines, symbols, text descriptions and other graphic elements to present the appearance, size, structure, pipeline and other information of the project in two-dimensional form. In the space enclosed by building components such as walls and slabs, it is necessary to arrange pipelines for water supply, drainage, heating, ventilation, strong and weak electricity, etc. The complicated spatial relationship between them is difficult to be accurate only by relying on floor plans, system diagrams, and large-scale diagrams of nodes. It is difficult for even experienced engineers to fully understand the information reflected in the drawings. In addition, if a good linkage mechanism is not established between various disciplines, design changes and drawing modifications will be difficult to complete systematically, which manifests as errors, omissions, and collisions during construction. The resulting rework increases the investment and prolongs the construction period.

\subsection{BIM technology is very intuitive}

The modeling and design process under BIM technology is based on the three-dimensional state, which is different from the traditional CAD-based design under the two-dimensional state. The use of BIM technology in the design stage can 
build a three-dimensional solid model of building components, can intuitively observe building components, analyze the functional layout of the building structure, and infer the building volume.

\subsection{Information sharing}

In the structural design of large-scale construction projects, the use of BIM visualization technology can dynamically demonstrate the building structure, inspect the size and conformity of the building structure, and determine the optimal design plan. By applying BIM technology to the coordinated design of different professions, the staff of each profession can realize the complete sharing of information, facilitate collaborative work, and can find out the errors, omissions and defects of drawings in time, and ensure the quality of architectural design. With the help of BIM technology in project management, it can ensure that the construction can be carried out in a normal and orderly manner.

\subsection{Collaborative design}

Before the start of construction, use the visual characteristics of the BIM model to coordinate the design of various disciplines (architecture, structure, water supply and drainage, electrical and mechanical, fire protection, elevators, etc.), and check the collision between various professional pipelines and the collision between pipelines and structures. Optimize the pipeline layout and raise the net height, improve the quality of the building, and reduce the problems of pipeline collision and removal and re-installation during construction.

\section{Application case of BIM technology in construction drawing review of a univer- sity construction project}

The total construction area of a university laboratory building is 73,370 square meters, including 5 floors above ground (partially 4 floors), with a construction area of 61,020 square meters, and 1 floor underground, with a construction area of 12,350 square meters. The above-ground part is divided into five buildings A, B, C, D, and E, which are connected by a corridor. In order to strengthen the pre-management of infrastructure projects and improve the quality of construction drawings to achieve the purpose of reducing later design changes and improving the accuracy of the engineering quantity list, the university entrusted professional institutions to use BIM-based digital construction technology to construct the laboratory building. The map is converted from a two-dimensional drawing to a three-dimensional model, so that the original complex spatial relationship between the various disciplines can be intuitively expressed.

\subsection{Comparison and selection of modeling software}

There are many BIM software vendors, and the software they develop has their own advantages and applicable fields. According to incomplete statistics, there are currently 70 models of BIM modeling software in the world, and there are 25 commonly used models. Mainstream BIM software mainly includes Autodesk Building Design Suite (including Revit series software), Tekla Structures software, Bentley software, ArchiCAD software, Digital Project software, Civil 3D software, etc.

Autodesk Building Design Suite is mainly used in the field of construction engineering. It contains BIM software such as Revit Architecture, Revit MEP, and Revit Structure. Among them, Revit Architecture is a 3D architectural design software that focuses on building models and structural configurations, using beams, plates, walls, and Doors and windows and other components are used as command objects to construct 3D building models to assist architects in building structure configuration and design; Revit MEP is an electromechanical system simulation platform, whose main functions are mechanical system planning, water supply and drainage system planning, ventilation pipeline configuration, power and lighting systems Line configuration, electromechanical system simulation, fire protection system planning, environmental load and cooling and heating system analysis, etc., can assist electromechanical engineers in the analysis and design of electromechanical and pipeline systems by constructing an integrated information model of electromechanical engineering; Revit Structure is a building structure construction model. Model software focuses on the configuration of structural systems such as reinforced concrete and steel structures of buildings, which can assist structural engineers in designing and analyzing building structural systems.

The advantage of Revit in BIM modeling is that it integrates different majors such as architecture, structure, and electromechanics. All participants play different roles in the Revit platform to achieve the purpose of information collaboration, information sharing, and information exchange. Therefore, according to the characteristics of the experimental building and the serialization, integration, maturity and universality of the modeling software, through a comparative analysis with other software, the Revit series software was selected for BIM modeling. ${ }^{[1]}$

\subsection{Build model}

First, start to build larger architectural model elements with volume setting or existing design, as well as defining floors 
and grids; second, placing general elements in the architectural model can assist in planning and configuration, and will be refined later. When designing, you can specify specific element types; third, create different architectural model views, such as sections, elevations, and 3D views. If you change the architectural model in one view, Revit will extend these changes to the entire project; fourth, after establishing the initial configuration, add more detailed items to the architectural model, including structure and system (MEP) components for Follow-up development and design; fifth, refined model.

\subsection{Create model file}

First, create a drawing of the model: generate a detailed drawing from the architectural model, or create a sketch show-ing specific details. Second, annotate the drawing: add annotations, text and tags to provide detailed information. Third, create a schedule: create a detailed list to determine the quantity and estimate the cost. Fourth, add detailed drawings: add detailed lines and detailed drawing components from the detailed drawing resource library. Add key notes to identify the required equipment and materials. Fifth, refine the drawing: after the drawing is created with the drawing, refine the appearance of the drawing. Sixth, publish the construction documents: print the construction documents, or publish them for electronic share. Seventh, track revisions: enter revision information, mark changes with revision clouds, and specify revisions to be displayed on each drawing.

\subsection{Collision detection and effect evaluation}

Using the built 3D model to deepen the design, each professional designer can intuitively discover the problems in the model space or complex parts of the node structure during the process of creating the 3D model. With the help of Navisworks, the integration of the professional 3D models is completed, and the collision is completed. In the inspection, 61 civil construction problems and 37 mechanical and electrical problems were unearthed.

In response to the civil engineering and electromechanical problems found in the collision detection, the school organized the design unit to modify the construction drawings. In the process of preparing the engineering quantity list, the school asked the entrusted engineering cost consulting unit to estimate the direct losses avoided by the adjustment of the construction drawings, and only assisted in the optimization of the space layout, avoiding rework, and reducing the consumption of construction materials and equipment. In terms of occupation and other aspects, the investment is reduced by more than one million yuan, which greatly exceeds the use cost of BIM technology, and the benefits are relatively obvious.

\section{Suggestions on the application of BIM technology in construction drawing exam- ination of university construction projects}

\subsection{Use BIM review as an important supplement to mandatory review}

In addition to the mandatory review required by the government, in order to solve problems such as the difficulty of finding errors caused by the difficulty of extracting information from traditional two-dimensional drawings, colleges and universities should entrust a professional institution to establish a BIM model, and check the architectural structure intersections and drawings that may exist in the construction drawings. Errors and collisions, optimization of electromechanical HVAC pipelines, net height analysis and other issues were investigated, and the "BIM Review Collision and Optimization Report" was issued as the main basis for optimization of construction drawings. In addition, a three-dimensional digital review system for construction projects and related supporting standards will be established to meet the needs and challenges of digital review work for BIM-based construction projects in the future. ${ }^{[2]}$

\subsection{Use the BIM review results as one of the basis for the evaluation of the design unit}

Errors, omissions, and collisions in construction drawings are often caused by the designers' inattentiveness and carelessness, and are the failure of the design unit to fulfill the contract. However, such problems often cause changes or even rework, and are the main source of construction claims for construction units, which are detrimental to the investment control and schedule control of college construction projects. In the process of managing design units, colleges and universities need to quantify the low-level errors in construction drawings. The BIM model and its collision detection method can solve this problem intuitively and efficiently.

\subsection{Meet the new requirements of current engineering management development}

The use of BIM technology in project construction is in line with the development trend and requirements of future engineering construction. The application of BIM technology in construction drawing design will have a positive effect on ensuring high efficiency and high quality in the project design, construction, and later operation and maintenance stages. At the same time, it is of great significance to further improve the project management ability and level, and to realize the refined 
management of the whole life cycle of the project. It also lays the data foundation for entering the operation and maintenance stage after the project is completed and delivered.After the prefabricated building under the EPC general contracting mode becomes the normal form of construction, the BIM digital model can be the carrier of engineering data and information. The builders collaborate more closely and efficiently. ${ }^{[3]}$

\section{Acknowledgments}

This paper was supported by the Fundamental Research Funds for the Central Universities Research on the Early-stage Management of Our School's Infrastructure Construction under the Background of Double First-class Construction" (Project number: 0211021SH0302038).

\section{References}

[1] Zhang Jisong,Zhao Lihua, Cui Yinghui, Ren Guoqian,Li Haijiang.Code compliance checking of structural design based on BIM model. Journal of graphics. 2021; 42(01): 133-140

[2] Liao Cancan, Ma Xiao, TAO Haibo. Research on 3D Digitization Review System of Construction Drawing. Intelligent Building \& Smart City. 2021; (02): 19-21.

[3] Huang Xuanan,Shi Yuexia,Chen Kenan,Jiang Fuchuan, Yin Pingxue.Research on the whole process information management and digital construction method of prefabricated building based on BIM technology. Journal of Information Technology in Civil Engineering and Architecture. 2021. 